\title{
PERANCANGAN MOBILE GAME BERDASARKAN PERMAINAN RAKYAT "DODOMBAAN" UNTUK MEMBANGUN INTERAKSI SOSIAL ANTAR PEMAIN
}

\author{
Raymond Ralibi, Achmad Syarief, Irfansyah \\ (Email: raymondralibi@gmail.com) \\ Program Studi Magister Desain \\ Fakultas Seni Rupa dan Desain \\ Institut Teknologi Bandung \\ Jl. Ganesha no. 10, Bandung, Indonesia.
}

\begin{abstract}
ABSTRAK
"Dodombaan" adalah permainan rakyat tempo dulu yang populer di kalangan anak-anak di Jawa Barat, meskipun saat ini ia sudah jarang dimainkan oleh anak-anak, karena mereka lebih menyukai permainan digital. Para Ahli yakin bahwa sebenarnya permainan rakyat ini memberikan kesempatan bagi anak-anak untuk mengembangkan rasa kepekaan sosial sebagai anak-anak karena mereka secara interaktif dapat bermain bersama. Melihat tingginya minat anak pada permainan digital dan manfaat sosial permainan rakyat, melalui proses studi maka akan dirancang dan dikembangkan sebuah permainan digital berdasarkan permainan rakyat Sunda -dodombaan. Proses studi desain ini dimulai dengan mengumpulkan dan menganalisis data para pemain dodombaan secara literal yang dilakukan untuk mendukung proses merancang permainan digital. Unsur-unsur formal permainan disesuaikan dengan permainan asli dari dodombaan. Hal ini dilakukan untuk memastikan bahwa pengguna akan memiliki pengalaman bermain sebenarnya serta mendapatkan manfaat sosial yang sama dari permainan ini. Permainan digital dodombaan dikembangkan sebagai mobile multi-player game pada platform android dan divisualisasikan sesuai dengan kesenian tradisional dari pertempuran domba (seni ketangkasan domba) dari Garut Jawa Barat. Diharapkan permaianan dodombaan ini dapat berfungsi sebagai produk alternatif permainan digital dengan konten budaya.
\end{abstract}

Kata kunci: Game konten budaya; Game mobile multiplayer; Permainan rakyat Sunda

\begin{abstract}
"Dodombaan" is an old and popular folk-game amongst children in West Java, although nowadays it becomes rarely played as many children are in favor of playing digital games. Scholars believe that this folk-game actually provides an opportunity for children to develop a sense of social-sensitiveness, as children interactively play with each other. Having exposed to children interests on digital games and the social benefit of Sundanese folk-game, the study sets to design and develop a digital-game based on Sundanese folk-game of dodombaan. This design-study started by collecting and analyzing data of users and plays of dodombaan, which iteratively done in support of the process of designing a digital game. The formal elements of game are composed according to the original game-play of dodombaan. This is to assure that users will have similar game-experiences and social-benefit of the play. The digital game of dodombaan is developed as a mobile multi-player game on android platform and visualized according to the traditional art of sheep's battle (seni ketangkasan domba) of Garut West Java. It is expected that the developed game of dodombaan can serve as an alternative product of digital game with cultural contents.
\end{abstract}

Keywords: Cultural content game; multiplayer mobile games; Sundanese folk-game 


\section{PENDAHULUAN}

Permainan rakyat "Dodombaan" adalah salah satu permainan yang digemari anak-anak di beberapa daerah di Jawa Barat. Permainan yang juga dikenal dengan nama hiehileudan ini biasanya dimainkan pada waktu libur sekolah atau waktu senggang lainnya. Namun, saat ini permainan rakyat "Dodombaan" semakin jarang dimainkan. Salah satu penyebabnya adalah anak-anak lebih memilih memainkan permainan digital atau game.

Cepatnya distribusi dan kuatnya penetrasi game digital, baik melalui internet maupun telepon seluler, membuat anak-anak hingga di pedesaan dengan mudahnya memiliki akses menuju game digital (Druin, 2009). Di samping itu, kemudahan akses terhadap permainan rakyat semakin berkurang. Permainan rakyat seperti "Dodombaan" biasanya menggunakan area tanah terbuka, sedangkan saat ini banyak area mulai ditumbuhi bangunan terutama di perkotaan. Permainan rakyat biasanya menggunakan peralatan dan perlengkapan yang berasal dari alam seperti bambu, dedaunan, bebatuan, biji-bijian, dan lain-lain. Perlengkapan tersebut hanya mudah didapatkan pedesaan. Kebanyakan permainan rakyat memerlukan waktu yang cukup lama untuk mempersiapkan dan memainkannya, sedangkan saat ini waktu bermain anak-anak dikorbankan dengan kegiatan sekolah, kursus, dan ekstrakurikuler (Gleave, 2009).

Kemudahan akses dan tingginya daya tarik game digital menimbulkan kekhawatiran akan terancamnya keberadaan permainan rakyat. Memang tidak semua game memiliki dampak negatif, namun game single-player adalah game yang paling sering ditemukan (Fullerton, 2008) dan game single-player adalah game yang paling rendah kemampuannya untuk membangun interaksi sosial (de Kort, IJsselsteijn, \& Poels, 2007). Sedangkan permainan rakyat seperti "Dodombaan" dapat membangun interaksi sosial antar pemain karena dimainkan oleh lebih dari satu orang. Mengacu pada kondisi tersebut, lahir sebuah gagasan untuk merancang sebuah game yang didasarkan dari permainan rakyat seperti "Dodombaan".

Permainan rakyat "Dodombaan" dipilih sebagai dasar perancangan game karena merupakan salah satu permainan yang dapat membangun interaksi sosial antar pemain. Interaksi sosial dapat terbangun selama permainan, yaitu mulai dari menyiapkan perlengkapan permainan, memainkan permainan, hingga pemberian hadiah dan hukuman bagi yang menang dan yang kalah. Selain itu, "Dodombaan" merupakan salah satu 
permainan yang digemari anak-anak di Jawa Barat dan salah satu permainan rakyat Sunda yang patut dilestarikan.

Rancangan game diwujudkan dalam bentuk mobile game karena saat ini hampir semua orang memilikinya dan distribusi game melalui perangkat mobile dapat dilakukan dengan cepat. Game lebih mudah diterima dan diapresiasi jika memiliki muatan menarik, bersifat menyatu, dan dekat dengan budaya dan masyarakat setempat. Oleh karena itu, konten seni ketangkasan domba garut (SKDG) di pilih sebagai konten visual dalam mobile game "Dodombaan".

\section{METODE PENELITIAN}

Pengumpulan data yang dilakukan bersifat kualitatif. Data diperoleh melalui observasi lapangan mengenai hal-hal yang terkait dengan permainan rakyat yang akan dikembangkan melalui mobile game. Observasi dilakukan untuk memahami aturan dan cara memainkan permainan, perlengkapan yang digunakan, pengkondisian pemain, dan sikap pemain saat memainkan permainan rakyat "Dodombaan". Wawancara pakar mobile game, pengguna mobile game dan calon pengguna juga dilakukan untuk memahami tanggapan dan harapan terhadap permainan rakyat dan mobile game yang akan dirancang. Selain itu juga dilakukan kaji literatur mengenai permainan rakyat, "Dodombaan", mobile game, interaksi sosial, dan topik-topik lain yang dapat dimanfaatkan untuk mendukung perancangan mobile game.

Hasil analisis berdasarkan data yang diperoleh digunakan untuk mendukung perancangan desain mobile game yang dilakukan melalui eksperimen secara iteratif. Tahapan iterasi mengacu dari Fullerton (2008) yang tahapannya terdiri dari brainstorming, prototipe fisikal, presentasi (opsional), prototipe digital, produksi, dan quality assurance (Fullerton, 2008). Selama tahapan tersebut, dibangun sebuah struktur mobile game "Dodombaan" yang didasarkan pada identifikasi permainan rakyat "Dodombaan". Struktur tersebut dibuat dalam bentuk elemen formal penyusun game dari Fullerton (2008).

\section{PEMBAHASAN}

Permainan "Dodombaan" adalah permainan dengan menggunakan media bunga rumput (bayam duri) yang diletakkan di atas karet atau tali. Kata "Dodombaan" merupakan kata ulang dengan kata dasar domba, sehingga "Dodombaan" berarti menyerupai domba. Nama 
tersebut diberikan karena bunga rumput menyerupai domba. Di beberapa daerah, permainan ini disebut dengan "Hiehileudan" yang artinya menyerupai hileud atau ulat, karena bentuk dan warna bunga rumput juga tampak seperti ulat. Cara memainkan "Dodombaan" adalah dengan meletakkan dua buah bunga rumput secara berhadapan di atas karet atau tali yang diikatkan di antara lidi atau paku sehingga membentuk rel. Para pemain hanya perlu memukul atau menggesek paku untuk menggetarkan sehingga bunga rumput atau "Dodombaan" tersebut maju hingga menabrak domba lainnya. Jika karet terus bergetar, maka salah satu domba akan terdesak dan jatuh keluar dari arena. Pemilik domba yang bertahan di atas karet dinyatakan sebagai pemenang.

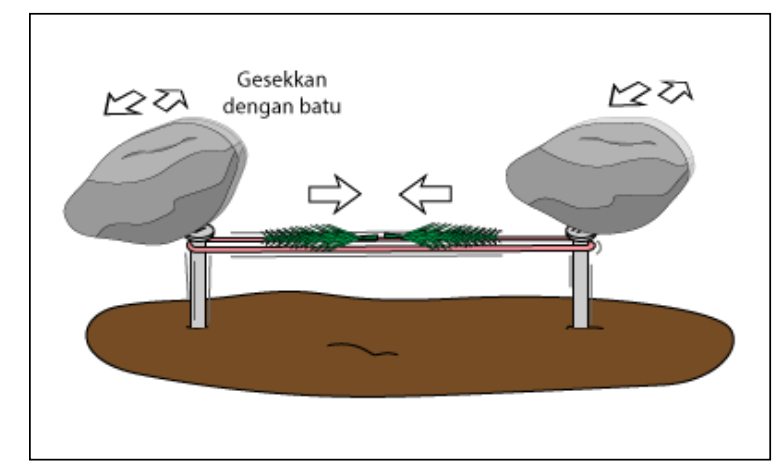

Gambar 1. Ilustrasi permainan rakyat "Dodombaan" Sumber: Dokumentasi Penulis, 2012

Permainan rakyat "Dodombaan" adalah salah satu permainan rakyat yang memiliki manfaat melatih kepekaan sosial, karena permainan ini dimainkan oleh dua orang atau lebih. Kepekaan sosial dilatih melalui interaksi antar pemain yang berlangsung selama proses permainan mulai dari permainan tersebut diajarkan, menyiapkan perlengkapan. Berikut beberapa interaksi sosial antar pemain yang mungkin terbangun pada permainan rakyat "Dodombaan":

(1) Berdiskusi untuk menyepakati bahwa mereka akan bermain "Dodombaan".

(2) Menyiapkan arena pertandingan permainan "Dodombaan".

(3) Bersama-sama mencari bunga rumput (bayam duri) sebagai domba.

(4) Menyepakati peraturan serta hadiah dan hukuman bagi pemenang dan yang kalah.

(5) Memposisikan "Dodombaan" (bunga rumput) dalam lintasan.

(6) Menggesek paku dengan batu atau memukul paku dengan kayu yang dapat membuat pemain lawan melakukan antisipasi.

(7) Menjatuhkan “Dodombaan" lawan.

(8) Bersorak kemenangan. 
(9) Menggendong pemenang jika kalah atau mendapatkan gendongan jika menang.

\section{Proses Desain}

Konsep perancangan mobile game "Dodombaan" yang didasarkan pada permainan rakyat "Dodombaan" adalah merancang mobile game tanpa banyak mengubah pengalaman dan cara bermainnya. Hal ini dimaksudkan agar fungsi permainan rakyat "Dodombaan" dalam membangun interaksi sosial antar pemain dapat dipertahankan.

Keuntungan lainnya adalah :

(1) Mobile game dapat lebih mudah dipahami jika pemain tersebut sudah pernah memainkan permainan rakyat "Dodombaan".

(2) Sebaliknya, pemain yang belum pernah memainkan "Dodombaan" tetapi mengetahui cara memainkan mobile game "Dodombaan", dapat mencoba permainan rakyat "Dodombaan" secara natural.

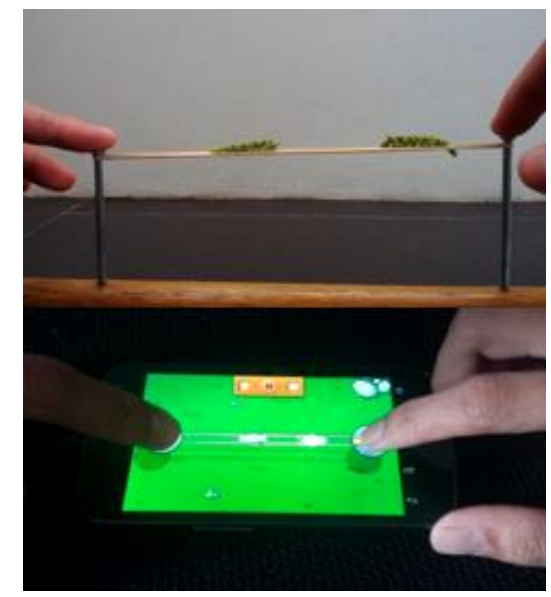

Gambar 2: Cara memainkan permainan rakyat "Dodombaan" (atas) dan dan cara memainkan mobile game "Dodombaan" (bawah)

Sumber: Dokumentasi Penulis, 2012

Perancangan game dengan mempertahankan pengalaman dan cara bermain, sukses diterapkan oleh produk game seperti Nintendo Wii, Dance Dance Revolution, dan iPhone steering wheel. Pengalaman saat bermain permainan "Dodombaan" dan penerapannya pada mobile game adalah

Sebagai berikut : 
Tabel 1. Perbedaan dasar "Dodombaan" pada sistem konvensional dan digital

\begin{tabular}{|c|c|}
\hline Permainan Rakyat “Dodombaan” & Mobile Game “Dodombaan” \\
\hline $\begin{array}{c}\text { Pemain memukul atau menggesek paku } \\
\text { dengan batu }\end{array}$ & Pemain menggesek layar mobile phone \\
dengan jarinya
\end{tabular}

Sumber: Dokumentasi Penulis, 2012

Dalam proses perancangan dirumuskan struktur mobile game "Dodombaan" yang dibuat dalam bentuk elemen formal penyusun game

menurut Fullerton (2008). Struktur ini dijadikan dasar dalam implementasi mobile game "Dodombaan".

Tabel 2. Elemen formal permainan rakyat "Dodombaan"

dan mobile game "Dodombaan" berdasarkan elemen formal dari Fullerton (2008)

\begin{tabular}{|c|c|}
\hline Permainan Rakyat “Dodombaan” & Mobile Game “Dodombaan” \\
\hline \multicolumn{2}{|l|}{ Pemain } \\
\hline $\begin{array}{l}\text { Dimainkan oleh dua orang. Syarat jumlah } \\
\text { pemain inilah yang memungkinkan } \\
\text { interaksi sosial antar pemain dapat } \\
\text { terbangun }\end{array}$ & $\begin{array}{l}\text { Dimainkan oleh dua pemain, tapi dapat juga } \\
\text { dimainkan seorang diri atau bersama } \\
\text { dengan pemain lain. Berikut } \\
\text { pengelompokkan mode pemain: } \\
\text { (1) Single-player } \\
\text { (2) Two-players dengan sebuah device yang } \\
\text { sama } \\
\text { (3) Two-players dengan dua buah device } \\
\text { (4) Multiplayer dalam sebuah kejuaraan } \\
\text { atau liga. }\end{array}$ \\
\hline
\end{tabular}




\begin{tabular}{|c|c|c|}
\hline \multicolumn{3}{|c|}{ Objektif } \\
\hline $\begin{array}{l}\text { Menjadi pemain yang dapat } \\
\text { mempertahankan domba di atas arena } \\
\text { melalui tandukan-tandukan sekaligus } \\
\text { mengeluarkan domba lawan dari arena }\end{array}$ & $\begin{array}{l}\text { Diba } \\
\text { (1) } \\
\text { (2) } \\
\\
\text { (3) }\end{array}$ & $\begin{array}{l}\text { agi menjadi tiga, yaitu: } \\
\text { Objektif battle/laga, objektif game } \\
\text { keseluruhan, dan objektif sampingan. } \\
\text { Objektif laga menyesuaikan objektif } \\
\text { permainan rakyat "Dodombaan" yaitu } \\
\text { menjadi pemain yang dapat } \\
\text { mempertahankan domba di atas arena } \\
\text { melalui tandukan-tandukan sekaligus } \\
\text { mengeluarkan domba lawan dari arena } \\
\text { Objektif game keseluruhan adalah } \\
\text { mengumpulkan poin setinggi- } \\
\text { tingginya. Poin tersebut merupakan } \\
\text { salah satu reward dari kemenangan- } \\
\text { kemenangan pada setiap pertandingan } \\
\text { yang dimainkan } \\
\text { Objektif sampingan adalah merawat } \\
\text { domba dan mengumpulkan badges } \\
\text { yang diperoleh dengan menyelesaikan } \\
\text { tantangan-tantangan di dalam game }\end{array}$ \\
\hline \multicolumn{3}{|c|}{ Prosedur } \\
\hline $\begin{array}{l}\text { (1) Letakkan domba (bunga rumput) } \\
\text { masing-masing di atas karet pada } \\
\text { sisinya masing-masing }\end{array}$ & $\begin{array}{l}(1) \\
(2)\end{array}$ & $\begin{array}{l}\text { Pemain menekan tombol 'Multiplayer' } \\
\text { Pemain menekan tombol '2-players } \\
\text { single device' }\end{array}$ \\
\hline $\begin{array}{l}\text { (2) Pukul atau gesek paku dengan batu } \\
\text { atau kayu }\end{array}$ & (3) & $\begin{array}{l}\text { Kedua pemain memilih masing-masing } \\
\text { domba (karakter) yang akan }\end{array}$ \\
\hline $\begin{array}{l}\text { (3) Terus memukul atau menggesek } \\
\text { hingga salah satu domba terjatuh }\end{array}$ & $\begin{array}{l}\text { (4) } \\
(5) \\
(6)\end{array}$ & $\begin{array}{l}\text { ditandingkan } \\
\text { Kedua pemain bersama-sama memilih } \\
\text { pamidangan atau arena tempat } \\
\text { pertandingan } \\
\text { Salah seorang pemain menekan tombol } \\
\text { 'start' } \\
\text { Setelah dimulai, kedua pemain dapat } \\
\text { menggesek gambar tiang paku pada }\end{array}$ \\
\hline
\end{tabular}




\begin{tabular}{|c|c|c|c|}
\hline & & (7) & $\begin{array}{l}\text { layar agar dombanya bergerak maju } \\
\text { Masing-masing pemain dapat menekan } \\
\text { tombol 'pause' untuk menghentikan } \\
\text { pertandingan sementara }\end{array}$ \\
\hline \multicolumn{4}{|c|}{ Aturan } \\
\hline & $\begin{array}{l}\text { Domba hanya diperbolehkan } \\
\text { diletakkan di sisi pemain } \\
\text { Domba tidak diperbolehkan disentuh } \\
\text { dengan apapun jika telah diletakkan di } \\
\text { atas karet }\end{array}$ & (1) & $\begin{array}{l}\text { Domba hanya diperbolehkan } \\
\text { diletakkan di sisi pemain (dilakukan } \\
\text { secara otomatis oleh game) } \\
\text { Domba tidak dapat disentuh atau tidak } \\
\text { memberikan reaksi jika disentuh }\end{array}$ \\
\hline (4) & $\begin{array}{l}\text { Pemain hanya diperbolehkan } \\
\text { memukul atau menggesek paku pada } \\
\text { sisinya masing-masing } \\
\text { Pemain yang dombanya berhasil } \\
\text { mengeluarkan domba lawan, } \\
\text { dinyatakan sebagai pemenang dan } \\
\text { lawannya dinyatakan kalah } \\
\text { Jika kedua domba keluar arena secara }\end{array}$ & $\begin{array}{l}\text { (3) } \\
\text { (4) }\end{array}$ & $\begin{array}{l}\text { Permainan terdiri dari beberapa ronde } \\
\text { Pemain yang lebih dahulu } \\
\text { mengeluarkan domba lawan, } \\
\text { dinyatakan memenangi ronde dan } \\
\text { mendapatkan satu ronde poin/bintang. } \\
\text { Pemain yang lebih dahulu mencapai } \\
\text { sejumlah poin yang disepakati, } \\
\text { dinyatakan sebagai pemenang }\end{array}$ \\
\hline & $\begin{array}{l}\text { bersamaan, maka domba yang } \\
\text { terakhir keluar dinyatakan sebagai } \\
\text { pemenang dan lawannya dinyatakan } \\
\text { kalah. Pertandingan juga dapat } \\
\text { dinyatakan seri/seimbang sesuai } \\
\text { kesepakatan antar pemain }\end{array}$ & (6) & $\begin{array}{l}\text { Masing-masing pemain hanya } \\
\text { diperbolehkan menggesek gambar } \\
\text { tiang paku pada sisinya masing-masing }\end{array}$ \\
\hline (6) & $\begin{array}{l}\text { Aturan pada tiap ronde jika } \\
\text { pertandingan dimainkan dalam } \\
\text { beberapa ronde: } \\
\text { a. Pemain yang memenangi ronde } \\
\text { dan mendapatkan satu poin, } \\
\text { lawannya tidak mendapat poin } \\
\text { b. Jika kedua domba keluar dari } \\
\text { arena, maka domba yang terakhir } \\
\text { keluar mendapat satu poin atau } \\
\text { keduanya tidak mendapatkan poin }\end{array}$ & & \\
\hline
\end{tabular}




\begin{tabular}{|c|c|}
\hline $\begin{array}{l}\text { (sesuai kesepakatan antar pemain) } \\
\text { (7) Pemain yang lebih dahulu mencapai } \\
\text { sejumlah poin yang disepakati, } \\
\text { dinyatakan sebagai pemenang }\end{array}$ & \\
\hline \multicolumn{2}{|c|}{ Sumber Daya } \\
\hline $\begin{array}{l}\text { Bunga rumput (bayam duri) merupakan } \\
\text { satu-satunya sumber daya yang dapat } \\
\text { digunakan untuk memenuhi objektif } \\
\text { permainan. Jika bunga rumput tersebut } \\
\text { terjatuh, pemain tidak dapat memenuhi } \\
\text { objektif permainan atau langsung } \\
\text { dinyatakan kalah }\end{array}$ & $\begin{array}{l}\text { (1) Domba garut merupakan metafora dari } \\
\text { bunga rumput } \\
\text { (2) Koin merupakan aset tambahan yang } \\
\text { dapat diperoleh dengan menyelesaikan } \\
\text { tantangan-tantangan dan mengikuti } \\
\text { kejuaraan. Koin-koin berguna untuk } \\
\text { membeli domba, membeli rumput, dan } \\
\text { aksesoris domba } \\
\text { (3) Rumput merupakan aset tambahan } \\
\text { yang dapat diperoleh dengan } \\
\text { memberikan latihan-latihan terhadap } \\
\text { domba seperti berenang di sungai atau } \\
\text { berjalan di bukit. Rumput berguna } \\
\text { untuk merawat dan meng-upgrade } \\
\text { domba }\end{array}$ \\
\hline \multicolumn{2}{|c|}{ Konflik } \\
\hline $\begin{array}{l}\text { Lawan dalam permainan itu sendiri. } \\
\text { Pemain lawanlah yang menghalangi } \\
\text { pemain untuk memenuhi memenangkan } \\
\text { permainan }\end{array}$ & $\begin{array}{l}\text { Sama dengan sumber konflik pada } \\
\text { permainan rakyat “Dodombaan” yaitu } \\
\text { pemain lawan. Terdapat juga konflik berupa } \\
\text { dilema dalam penentuan komponen yang } \\
\text { akan di-upgrade }\end{array}$ \\
\hline \multicolumn{2}{|c|}{ Batasan } \\
\hline $\begin{array}{l}\text { Karet yang menghubungkan dua buah } \\
\text { paku. Dalam permainan, domba harus } \\
\text { diletakkan di atas karet tersebut. Domba } \\
\text { tidak dapat diletakkan di luar karet atau } \\
\text { domba yang ada di luar karet bukan bagian } \\
\text { dari permainan }\end{array}$ & $\begin{array}{l}\text { Arena yang direpresentasikan dengan karet } \\
\text { yang menghubungkan dua buah tiang paku. } \\
\text { Domba dalam permainan harus tetap } \\
\text { berada di atas arena }\end{array}$ \\
\hline & \\
\hline
\end{tabular}




\begin{tabular}{|l|l|}
\hline Jika pemain menjadi pemenang, maka & Sama dengan hasil pada permainan rakyat \\
pemain lainnya kalah dan sebaliknya atau & "Dodombaan”. Selain itu keseluruhan hasil \\
keduanya seri/seimbang yaitu tidak ada & dari setiap pertandingan dapat diakumulasi \\
yang menjadi pemenang ataupun & untuk dibandingkan dengan akumulasi hasil \\
mendapat kekalahan & pemain-pemain lain untuk menentukan \\
& peringkat pemain \\
\hline
\end{tabular}

Sumber: Dokumentasi Penulis, 2012

Interaksi sosial yang terbangun dari mobile game "Dodombaan" dapat teridentifikasi berdasarkan pola interaksi antar pemain. Mobile game "Dodombaan" memiliki tiga dari tujuh pola interaksi antar pemain oleh Fullerton (2008), yaitu sebagai berikut:

\section{(1) Single-player versus Game}

Pola interaksi ini terdapat pada mode single-player. Pada mode ini, interaksi sosial tidak terbangun langsung/tetunda. Interaksi sosial hanya dapat terjadi jika pemain menceritakan pengalaman bermainnya dengan pemain lain jika ditemukan dan jika mau menceritakan. Interaksi sosial juga dapat terbangun jika mode ini dimainkan ketika ada orang yang melihat. Efek interaksi sosial mode ini dapat dikatakan sama dengan game single-player lainnya.

(2) Player versus Player

Pola interaksi ini terdapat pada mode two-players dengan sebuah device dan twoplayers dengan dua buah device melalui bluetooth. Pada mode ini, interaksi sosial antar pemain dapat terbangun secara langsung. Jika melihat interaksi sosial yang terbangun pada pemainan rakyat "Dodombaan", mode ini memungkinkan untuk membangun hampir semua interaksi sosial pada permainan rakyat "Dodombaan" yang disebutkan pada bagian pembahasan.

\section{(3) Multilateral Competition}

Pola interaksi ini terdapat pada mode multiplayer. Mode multiplayer diakomodasi melalui fitur kejuaraan atau liga. Fitur ini memanfaatkan layanan jejaring sosial populer seperti Facebook dan Twitter yang sehingga pemain dapat melihat teman-temannya yang juga memainkan "Dodombaan", mengundang temannya yang belum memainkan "Dodombaan", menantang temannya dalam laga, liga, atau kejuaraan "Dodombaan". Riwayat pertandingan setiap pemain, pertandingan pada liga yang berlalu, atau yang akan datang dapat dicatat sehingga dapat dijadikan topik diskusi antar pemain. 
Interaksi sosial antar pemain seperti ini merupakan kelebihan mobile game "Dodombaan" dari permainan rakyatnya.

Game lebih mudah diterima dan diapresiasi jika memiliki muatan menarik, bersifat menyatu, dan dekat dengan budaya dan masyarakat setempat. Oleh karena itu, konten seni ketangkasan domba garut (SKDG) dipilih sebagai konten visual dan sumber inspirasi dalam perancangan mobile game "Dodombaan". Aspek visual mobile game "Dodombaan" yang dirancang terdiri dari beberapa unsur di antaranya: warna, karakter, tipografi, layout (environment), dan komponen pelengkap seperti unsur musik, ilustrasi penonton, umpanbalik, dan lain-lain.

Mobile game "Dodombaan" diwujudkan pada platform Android minimal versi 2.3 dengan kemampuan layar sentuh pada device. Hasil game dapat di-download pada Google Play (https://play.google.com/store/apps/details?id=com.ralibi."Dodombaan"_rc).

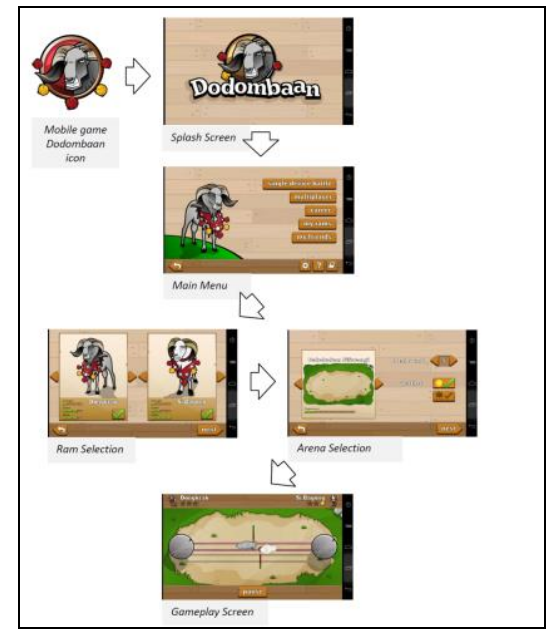

Gambar 3: Cuplikan gambar dari implementasi game dengan konten visual SKDG pada alur utama game two players dengan sebuah device yang sama Sumber: Dokumentasi Penulis, 2012

\section{PENUTUP}

"Dodombaan" merupakan permainan rakyat yang semakin jarang dimainkan. Anak-anak lebih memilih permainan game digital dibandingkan dengan permainan rakyat. Tingginya daya tarik game dikhawatirkan mengancam keberadaan permainan rakyat. Permainan rakyat dapat tetap dinikmati dengan merancang game yang didasarkan pada permainan rakyat. Dengan mempertimbangkan minat anak-anak terhadap game dan sekaligus mempertahankan nilai-nilai positif yang ada pada permainan rakyat, maka dirancanglah 
mobile game yang dapat membangun interaksi sosial antar pemain yang didasarkan pada permainan rakyat "Dodombaan" dengan konten seni ketangkasan domba garut (SKDG).

Mobile game "Dodombaan" yang dirancang menyesuaikan identifikasi permainan rakyat "Dodombaan". Jumlah pemain pada mobile game menyesuaikan permainan rakyat "Dodombaan" agar mobile game "Dodombaan" tetap memiliki kemampuan untuk membangun interaksi sosial antar pemain. Strategi lain yang digunakan untuk membangun interaksi sosial antar pemain adalah dengan memanfaatkan layanan jejaring sosial seperti Facebook dan Twitter.

Konten visual mobile game "Dodombaan" didasarkan pada SKDG yang disertakan secara eksplisit pada mobile game. Konten tersebut di antaranya domba Garut sebagai karakter utama, pamidangan sebagai lingkungan dan arena pertandingan, wasit dan pendamping sebagai karakter pelengkap. Konten audio seperti musik kendang penca yang selalu mengiringi SKDG juga disertakan dalam mobile game.

Penelitian ini hanya membahas interaksi sosial yang terbangun antar pemain saat memainkan permainan rakyat "Dodombaan". Masih banyak interaksi sosial yang terbangun di luar interaksi antar pemain. Untuk penelitian selanjutnya, diharapkan juga membahas interaksi sosial yang terjadi antara pemain dengan masyarakatnya. Hal ini tidak hanya berlaku pada penelitian terhadap permainan rakyat "Dodombaan" saja, tetapi juga diterapkan pada permainan rakyat yang lain.

\section{DAFTAR PUSTAKA}

de Kort, Y. A., IJsselsteijn, W. A., \& Poels, K. (2007). Digital games as social presence technology: Development of the Social Presence in Gaming Questionnaire (SPGQ). In Proceedings of PRESENCE 2007: The 10th International Workshop on Presence, (page 195-203).

Druin, A. (2009). Mobile Technology for Children. Massachusetts: Morgan Kaufmann.

Fullerton, T. (2008). Game Design Workshop (2nd Edition). Burlington: Morgan Kaufmann.

Gleave, J. (2009). Children's Time to Play: A Literature Review. Lo 